\title{
Determination of the efficacy of ultrasound combined with essential oils on the decontamination of Salmonella inoculated lettuce leaves
}

\author{
D. Millan-Sango a , E. Garroni a , C. Farrugia ${ }^{\text {b }}$, J.F.M. Van Impe ${ }^{\text {c, }}$ V.P. Valdramidis ${ }^{\text {a, }}{ }^{*}$ \\ a Department of Food Studies and Environmental Health, University of Malta, Msida, Malta \\ b Department of Chemistry, University of Malta, Msida, Malta \\ ${ }^{\mathrm{c}}$ Department of Chemical Engineering BioTeC - Chemical and Biochemical Process Technology and Control, Katholieke Universiteit Leuven, Gent, Belgium
}

\section{A R T I C L E I N F O}

\section{Article history:}

Received 23 December 2015

Received in revised form

16 May 2016

Accepted 20 May 2016

Available online 24 May 2016

\section{Keywords:}

Ultrasound

Salmonella

Fresh produce

Decontamination

\begin{abstract}
A B S T R A C T
Salmonella is one of main pathogenic bacteria present in fresh produce. Ultrasound has been reported to be effective at inactivating food-borne pathogens. Moreover, ultrasound can be combined with essential oils to enhance its efficacy. This study evaluates the reduction and inactivation of Salmonella enterica Abony inoculated on lettuce leaves by the application of continuous and pulsed ultrasound as well as ultrasound combined with the essential oil of oregano and thyme. The physicochemical properties of these essential oil nanoemulsions are characterised while the structural damage of treated leaves is determined by the electrolyte leakage. Ultrasound combined with essential oils enhanced the microbial reduction on lettuce leaves and inactivation on the treated water, resulting on significant differences at concentrations higher than $0.018 \%(\mathrm{v} / \mathrm{v}$ ) compared to control. Particle size, zeta potential and $\mathrm{pH}$ varied between 35 and $133 \mathrm{~nm},-26$ to $-36 \mathrm{mV}$ and 5.67 to 5.38, respectively. Electrolyte leakage was similar for both the control and the treated samples, increasing when essential oils were applied.
\end{abstract}

() 2016 Elsevier Ltd. All rights reserved.

\section{Introduction}

Salmonella is one of major bacterial challenges of food safety and it is responsible for numerous foodborne illnesses around the world. In the United States, Salmonella enterica causes 1.2 million illnesses each year (Jackson, Griffin, Cole, Walsh, \& Chai, 2013). In Europe, the European Food Safety Authority estimates that over 100,000 human cases of Salmonella illnesses are reported each year. The presence of Salmonella on these products is an important health issue related with food safety issues as fresh fruits and vegetables are consumed raw. Hence, they have been catalogued as high risk food products. Moreover, in recent years, there has been an increment of consumption of fresh vegetables and fruits due to their health benefits linked to the prevention of chronic diseases, such as heart disease, cancer, diabetes, and obesity (Callejón et al., 2015). Therefore, the food industry has to implement sound and safe decontamination technologies to ensure high availability of safe fresh produce to the consumers.

Washing with sanitizers, especially chlorine-based products, is the most common decontamination technology applied by the food

\footnotetext{
* Corresponding author.

E-mail address: vasilis.valdramidis@um.edu.mt (V.P. Valdramidis).
}

industry. However, increasing public health concerns about the possible formation of trihalomethanes, which have been reported for possible carcinogenic effects (Dunnick \& Melnick, 1993) and legislation about controlling the use of chlorine, makes the need to find new decontamination technologies imperative (Fernandez, Noriega, \& Thompson, 2013).

Recent studies have shown the efficacy of several new decontamination technologies in order to assess the microbial safety of the fresh produce (Allende, Tomás-Barberán, \& Gil, 2006; Gil, Selma, López-Gálvez, \& Allende, 2009; Gómez-López, Rajkovic, Ragaert, Smigic \& Devlieghere, 2009; Rico, Martin-Diana, Barat, \& Barry-Ryan, 2007; Ölmez \& Kretzschmar, 2009). Among them, ultrasound is a non-thermal technology, able to inactivate microorganisms, which is acquiring importance within the food industry because is reasonably inexpensive and energy saving (Awad, Moharram, Shaltout, Asker, \& Youssef, 2012). . Its antimicrobial efficacy is related to two main mechanisms, namely, cavitation and sonolysis. During cavitation, bubbles generated by ultrasound collapse, producing areas of high temperature (approximately $5500{ }^{\circ} \mathrm{C}$ ) and pressure (approximately $50 \mathrm{MPa}$ ) (Mukhopadhyay \& Ramaswamy, 2012). The high temperatures and pressures created within the bubble are responsible for the generation of hydrogen atoms and hydroxyl radicals, resulting in the phenomenon called 
sonolysis (Riesz, Berdahl, \& Christman, 1985). These mechanisms damage the cellular and functional components of microorganisms and therefore result in cell lysis (Chemat \& Khan, 2011). However, ultrasound alone is not very effective in inactivating bacteria on food (Piyasena, Mohareb, \& Mckellar, 2003). Ultrasound can be combined with other decontamination technologies for enhancing microbial inactivation (Sango, Abela, McElhatton, \& Valdramidis, 2014). The effect of cavitation generated by the ultrasound appeared to enhance the removal of attached or entrapped cells on the surfaces of fresh produce, rendering the bacteria more susceptible to antimicrobial sanitizers (Seymour, Burfoot, Smith, Cox, \& Lockwood, 2002). Essential oils such as oregano or thyme are natural sanitizers and they are considered as Generally Recognized as Safe (GRAS) food ingredients and can be used as postharvest treatment for controlling bacteria growth. Their antimicrobial efficacy is related to their chemical composition, where the phenolic components are the main compounds responsible for bacterial inactivation (Burt, 2004, Cosentino et al., 1999). Different mechanisms have been described to explain this antimicrobial mechanism: degradation of the bacterial wall (http://www.sciencedirect. com/science/article/pii/S0963996914006905 Helander, Alokomi, Latva-kala, Mattila-Sandhlom, Pol, Smid, Gomis, \& Von Wright, 1998), damage of the cytoplasmic membrane (http://www. sciencedirect.com/science/article/pii/S0963996914006905Ultee, Kets, \& Smid, 1999), coagulation of the cytoplasm (http://www. sciencedirect.com/science/article/pii/

S0963996914006905Gustafson et al., 1998), depletion of the proton force (Ultee \& Smid, 2001) and increase of the cell membrane permeability, producing leaking of the intracellular constitutes (http://www.sciencedirect.com/science/article/pii/

S0963996914006905Lambert, Skandamis, Coote, \& Nychas, 2001).

Additionally, ultrasound is able to generate nanoemulsions. Nanoemulsions are oil-in-water or water-in-oil dispersions with a droplet size in the range of $20-200 \mathrm{~nm}$ and showing narrow size distributions (Solans, Izquierdo, Nolla, Azemar, \& Garcia-Celma, 2005). The small size of the droplets generated during the process enhances the bioactivity of the disperse medium due to an increment of the contact surface. Moreover, nanoemulsions can improve the stability of the dispersion (Solans et al., 2005) which can be determined by the $\mathrm{z}$-potential.

The aim of this study was to assess the efficacy of ultrasound, alone or combined with two essential oils (namely essential oil of oregano (EEO) and thyme (EOT)), on the decontamination of lettuce leaves inoculated with Salmonella. Moreover, the presence of the bacteria in water after the studied decontamination processes was evaluated. Reduction levels on the surface of the fresh lettuce and the presence of Salmonella in water were used to calculate the total inactivation efficacy of the different decontamination set-ups. The physicochemical characterization (i.e. particle size, z-potential, $\mathrm{pH}$ ) of the EOS/water nanoemulsions generated by the different ultrasound set-ups was also determined while the damage of lettuce leaves treated by ultrasound was analysed by the electrolyte leakage rate.

\section{Materials and methods}

\subsection{Bacterial strain and inoculum preparation}

Salmonella enterica, serotype Abony 6017 was obtained from the National Collection of Types Cultures (Health Protection Agency, Salisbury, England) in a lyophilised form. The bacterial cultures were prepared in beads and kept in vials in a freezer at $-70{ }^{\circ} \mathrm{C}$. A bead was taken from the vial and streaked on Tryptic Soya Agar (TSA) (Oxoid, UK) plates, which were incubated for $24 \pm 2$ h at $37^{\circ} \mathrm{C}$, in order to obtain single colonies. Thereafter, the plates were stored at $4{ }^{\circ} \mathrm{C}$ for a maximum of one month. A single colony from the stock culture was picked with a loop under sterile conditions and transferring to $9 \mathrm{~mL}$ of Tryptic Soya Broth without dextrose (Scharlau, Spain) (TSB-D) and then incubated at $37^{\circ} \mathrm{C}$ for $24 \pm 2 \mathrm{~h}$. A subculture was prepared by transferring $10 \mu \mathrm{L}$ of the initial culture to $100 \mathrm{mLTSB}-\mathrm{D}$, incubated overnight at $37^{\circ} \mathrm{C}$ allowing the bacteria to reach stationary phase $\left(10^{8}-10^{9} \log \mathrm{CFU} / \mathrm{mL}\right)$. In order to obtain the final inoculum, $5 \mathrm{~mL}$ of the suspension was centrifuged $(6400 \times g)$ for $20 \mathrm{~min}$ (Benchtop Centrifuge 2-16P, Sartorious, Goettingen, Germany) and washed with Ringer's solution (Scharlau, Sentmenat, Spain) twice, resulting in a concentration of $10^{6} \mathrm{CFU} / \mathrm{mL}$.

\subsection{Preparation of the lettuce}

Fresh Romain lettuces (Lactuca sativa L. var. longifolia) were purchased from a local supplier and kept in refrigeration conditions at $4{ }^{\circ} \mathrm{C}$. For the experiments, damaged outer leaves of the lettuce were removed. Medium and inner leaves were washed with tap water for 30-60 s to eliminate any presence of soil or other material, and then they were gently dried with absorbing paper to drain the water excess. Lettuce leaves were cut using a scalpel into pieces of $4 \times 4 \mathrm{~cm}$ and placed under a UV $\operatorname{lamp}(\lambda=253.7 \mathrm{~nm})$ in a laminar flow cabinet (Microflow Peroxide Class II, Bioquell, Andover, England) for $15 \mathrm{~min}$ each side in order to eliminate the lettuce's natural flora.

\subsection{Challenge tests}

$100 \mu \mathrm{L}$ of the fresh inoculum of Salmonella was inoculated on one side of the lettuce samples through spot inoculation. Inoculated samples were dried for $1 \mathrm{~h}$ in a laminar flow cabinet in order to allow bacterial attachment. After $1 \mathrm{~h}$ samples were turned over and the same bacterial attachment protocol described above was repeated on the other side. Experimental samples consisted of 6 pieces of lettuce inoculated on both sides, giving a total inoculated area of $192 \mathrm{~cm}^{2}$.

After inoculation, samples were placed in an empty sterilized beaker, together with $500 \mathrm{~mL}$ of sterilized distilled water. Ultrasound treatments were performed with an ultrasonic system (UP 200ST, Hielscher Ultrasonic, Teltow, Germany) operating at $26 \mathrm{kHz}$, $90 \mu \mathrm{m}, 200 \mathrm{~W}$ attached with a probe of $14 \mathrm{~mm} \emptyset$ which was submerged $(3 \mathrm{~cm})$ into the water with the samples. The same processing time (300 s) was applied through continuous or pulsed mode. Three different set-ups were applied for the pulsed mode (i) $10 \mathrm{~s}$ on/ $6 \mathrm{~s}$ off, (ii) $5 \mathrm{~s}$ on $/ 5 \mathrm{~s}$ off and (iii) $2 \mathrm{~s}$ on/ $8 \mathrm{~s}$ off. Therefore, the total treatment time was $5 \mathrm{~min}$ for continuous, $8 \mathrm{~min}$ for $10 \mathrm{~s}$ on $/ 6 \mathrm{~s}$ off ( $300 \mathrm{~s}$ on (30 pulsed 'on' of $10 \mathrm{~s}$ )/180 s off (30 pulsed 'off' of $6 \mathrm{~s}$ ), $10 \mathrm{~min}$ for $5 \mathrm{~s}$ on $/ 5 \mathrm{~s}$ off ( $300 \mathrm{~s}$ on (60 pulsed 'on' of $5 \mathrm{~s}) / 300 \mathrm{~s}$ off ( 60 pulsed 'off' of $5 \mathrm{~s}$ ) and $25 \mathrm{~min}$ for $2 \mathrm{~s}$ on/ $8 \mathrm{~s}$ off ( $300 \mathrm{~s}$ on ( 150 pulsed 'on' of $2 \mathrm{~s}$ )/ $1500 \mathrm{~s}$ off ( 150 pulsed 'off' of $8 \mathrm{~s}$ )). Control samples were immersed in $500 \mathrm{~mL}$ of sterile dissolved water and kept unsonicated for the different treatment times corresponding to the same treatment applied to the ultrasound treated samples $(5,8,10$ and $25 \mathrm{~min}$ ). The maximum temperature achieved for the different ultrasound treatments was below $45{ }^{\circ} \mathrm{C}$ in order to avoid any bacterial heat stress.

Additionally, continuous ultrasound and $2 \mathrm{~s}$ on/8 $\mathrm{s}$ off of the ultrasound pulsed mode were combined with several concentrations $(0.010 \%, 0.014 \%, 0.018 \%, 0.022 \%$ and $0.025 \% \mathrm{v} / \mathrm{v})$ of EOO (Ecopharm Hellas, Thessaloniki, Greece) or EOT (BioAroma, Crete, Greece). Furthermore, control of EOO and EOT were performed at the concentrations described previously for either 5 or $25 \mathrm{~min}$. According to the manufacturer the chemical composition of the main components of the EOO were carvacrol $(75-85 \% \mathrm{v} / \mathrm{v})$ and 
thymol $(0.7-4 \% \mathrm{v} / \mathrm{v})$, and those of EOT were carvacrol $(51.6 \% \mathrm{v} / \mathrm{v})$, thymol $(21.7 \% \mathrm{v} / \mathrm{v})$ and $\gamma$-terpinene $(8.2 \% \mathrm{v} / \mathrm{v})$. Three replicates were carried out for each experiment.

\subsection{Assessment of the microbial reduction and total efficiency of the treatments}

Control and treated samples were transferred into a stomacher bag under sterile conditions. $30 \mathrm{~mL}$ of Ringer's solution was added and the mixture homogenized for $2 \mathrm{~min}$ in a stomacher device (BagMixer 400P, Interscience, Saint Nom, France). The microbial load of the washing water after all experiments was determined. Serial dilutions of homogenized lettuce samples and washing water were performed and the appropriate dilution was spread on TSA. Samples were incubated at $37^{\circ} \mathrm{C}$ for $24 \mathrm{~h}$. Low microbial population counts were assessed by plating $1 \mathrm{~mL}$ of the sample over three TSA plates according to ISO 7218:2007.

Inactivation levels of the different studied decontamination technologies (ultrasound treatment alone, and in combination with EOO and EOT) and the control samples were determined. For this purpose, the survival population on lettuce leaves and in water was calculated. The obtained value was subtracted from the initial population inoculated on the lettuce, obtaining the total inactivation levels.

\subsection{Determination of the physicochemical properties of the nanoemulsions}

The refractive index of the studied essential oils was measured using a refractometer (Abbe refractometer 1T/4T, Atago, Tokyo, Japan) at $24{ }^{\circ} \mathrm{C}$. The particle size of the nanoemulsions of different concentrations of EOO or EOT, generated by ultrasound (continuous or pulsed mode), were analysed by dynamic light scattering (DLS) with a Zetasizer Nano ZS laser light scattering instrument (Malvern Instruments Ltd, Worcestershire, UK) in order to determine accurately the diameter of droplets in the submicron range. The measurements were performed at $633 \mathrm{~nm}$ and $25^{\circ} \mathrm{C}$, the instrument being equipped with non-invasive backscatter $\left(173^{\circ}\right)$.

The z-potential of the same nanoemulsions, described previously, was determined by phase-analysis light scattering (PALS) with a Zetasizer Nano ZS laser light scattering instrument (Malvern Instruments Ltd, Worcestershire, UK). This provided information about the surface charge at the interface of the droplets dispersed in the nanoemulsion.

$\mathrm{pH}$ values of the sonicated samples (continuous and pulsed ultrasound) and nanoemulsions generated by continuous or pulsed ultrasound in combination with the concentrations of EOO or EOT described above were determined by a $\mathrm{pH}$ meter (Jenway, Staffordshire, UK).

\subsection{Electrolyte leakage rate}

The electrolyte leakage rate (ER) was measured following the protocol described by Fan and Sokorai (2005) with some modifications. Six pieces of Romain lettuce leaves of $4 \times 4 \mathrm{~cm}$ were treated with the ultrasound set ups described above (alone or in combination with the EOO or EOT). After the ultrasound process, samples were placed in a Duran bottle containing $200 \mathrm{~mL}$ of distilled water and shaken gently. Electrical conductivity of the solution was measured at $1 \mathrm{~min}\left(\mathrm{C}_{1}\right)$ and $60 \mathrm{~min}\left(\mathrm{C}_{60}\right)$ of incubation using a conductivity meter (Jenway, Staffordshire, UK). The samples were then autoclaved $\left(121^{\circ} \mathrm{C}\right)$ for $15 \mathrm{~min}$, and total conductivity $\left(\mathrm{C}_{\mathrm{T}}\right)$ of solution was measured after cooling. ER was calculated from the following equation: $\mathrm{E}=\left(\mathrm{C}_{60}-\mathrm{C}_{1}\right) / \mathrm{C}_{\mathrm{T}} \times 100$.

\subsection{Statistical analysis}

Statistical analysis was carried out by IBM SPSS statistic 23 (Armonk, New York, U.S.). In order to determine significant differences among the treatments, an ANOVA test was carried out using the Tukey test at $5 \%$ probability.

\section{Results}

\subsection{Ultrasound treatments}

Control samples reduced the presence of Salmonella on the lettuce leaves by about $1 \log \mathrm{CFU} / \mathrm{cm}^{2}$. Ultrasound continuous mode reduced Salmonella on the surface of the lettuce leaves to $2.23 \pm 0.29 \log \mathrm{CFU} / \mathrm{cm}^{2}$. Ultrasound pulsed mode led a microbial reduction ranged between 1.68 and $1.78 \log \mathrm{CFU} / \mathrm{cm}^{2}$. No statistical differences were observed among pulsed modes (Fig. 1). However, significant difference was noted between continuous ultrasound and pulsed modes. Ultrasound treatments (continuous and pulsed modes) showed less than $1 \log$ CFU/sample in terms of total inactivation (Fig. 2). No significant differences were found among the treatments. Control samples showed a negligible value in terms of decontamination.

\subsection{Essential oils treatments}

EOO and EOT control treatments are reported in Table 1. Higher levels of bacteria reduction on the surface were observed when the concentration of essential oils (i.e., oregano and thyme) increased. However, the levels of total bacteria inactivation (i.e., including also the microbial reduction in the water) were below $1 \log \mathrm{CFU} / \mathrm{sample}$ in all cases.

\subsection{Ultrasound treatments in combination with essential oils}

Reduction levels of the bacteria treated with EOO and EOT combined with continuous and pulsed mode (2s on/8 s off) are shown in Fig. 3. When EOO was combined with ultrasound continuous or pulsed mode (2 s on/8 s off), similar behaviours regarding the reduction of Salmonella on the surface of the lettuce leaves were observed. Comparable levels of reductions were observed at low concentrations of EOO $(0.010 \%$ and $0.014 \% \mathrm{v} / \mathrm{v})$. However, at $0.018 \% \mathrm{v} / \mathrm{v}$ of EEO, reduction levels increased up to $3.08 \pm 0.30$ and $2.95 \pm 0.25 \log \mathrm{CFU} / \mathrm{cm}^{2}$ for continuous and pulsed mode sonication, respectively. In addition, the highest concentrations of EOO $(0.025 \% \mathrm{v} / \mathrm{v})$ resulted in a reduction of the levels of Salmonella below the limit of detection in both set-ups. The same tendency was observed when EOT was applied in combination with either continuous or pulsed ultrasonication. Low concentrations of EOT $(0.010$ and $0.014 \% \mathrm{v} / \mathrm{v})$ resulted in similar levels of reduction compared with ultrasound without essential oil. $0.018 \% \mathrm{v} / \mathrm{v}$ of EOT notably increased the level of reduction of the studied bacteria on the surface of the lettuce, up to $3 \log \mathrm{CFU} / \mathrm{cm}^{2}$, compared with ultrasound in the absence of essential oil. In terms of total bacteria inactivation (namely, both in water and lettuce surfaces) EOT was more effective than EOO (Fig. 4). However, the lowest concentration of both essential oils $(0.010 \% \mathrm{v} / \mathrm{v})$ in combination with either continuous or pulsed ultrasound showed similar levels of total inactivation compared to ultrasound in the absence of essential oil. Similarly, essential oil concentrations higher than $0.018 \%$ showed significant differences with the other tested treatments.

\subsection{Analysis of refractive index, particle sizes, z-potential, $p H$}

The refractive index of the EEO was 1.51487 , while the value 


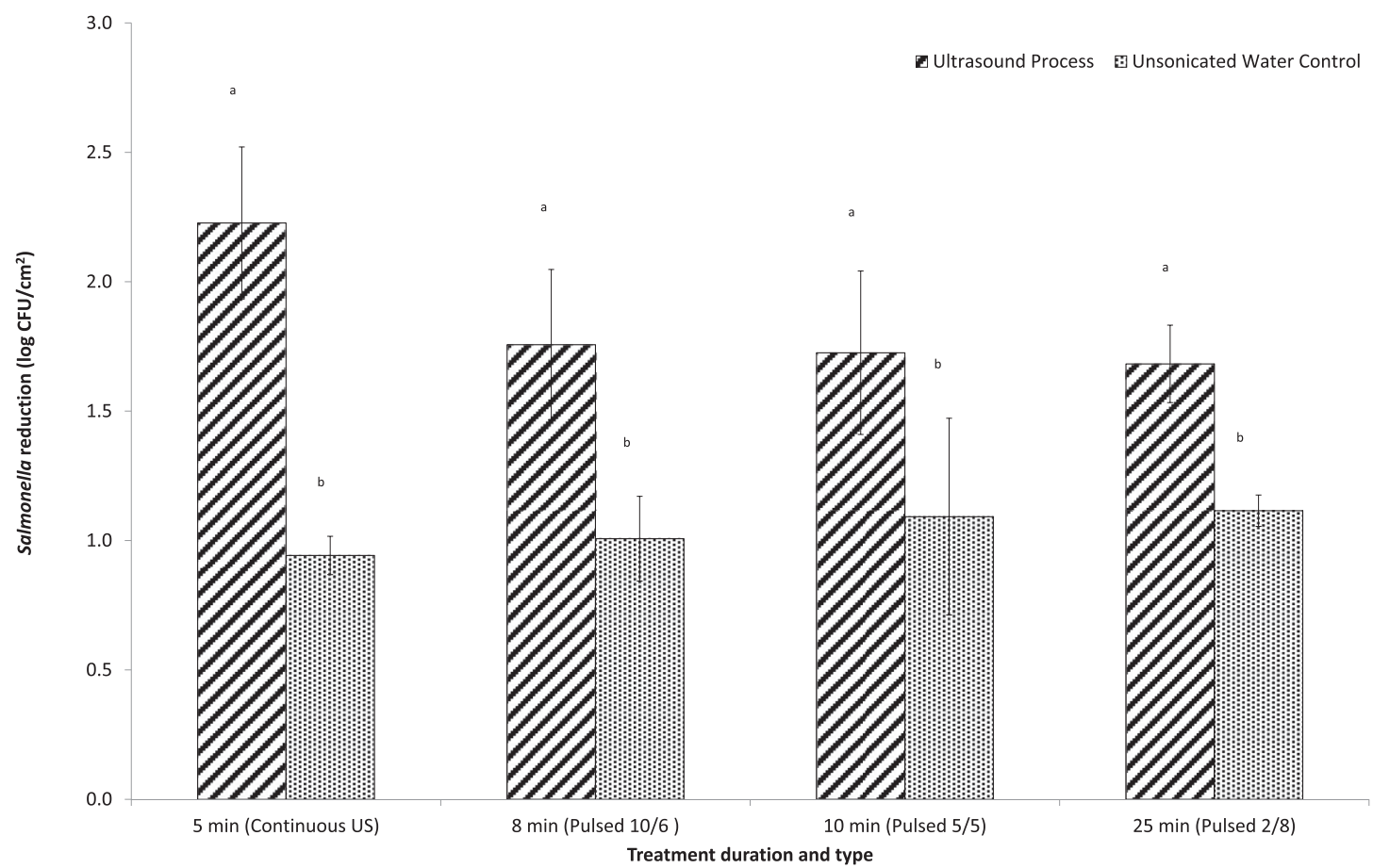

Fig. 1. Reduction levels of Salmonella enterica on the surface of Romaine lettuce after washing with water or ultrasound treatment $(p<0.01)$.

obtained for EET was 1.50084, which is expected, considering that their main chemical composition consists of carvacrol and thymol. EOO dispersions generated by continuous ultrasound resulted in a particle size between 68.06 and $105.70 \mathrm{~nm}$, while pulsed ultrasound produced particles between 44.07 and $108.80 \mathrm{~nm}$ (Table 2). Nanoemulsions of EOT created by continuous ultrasound exhibited

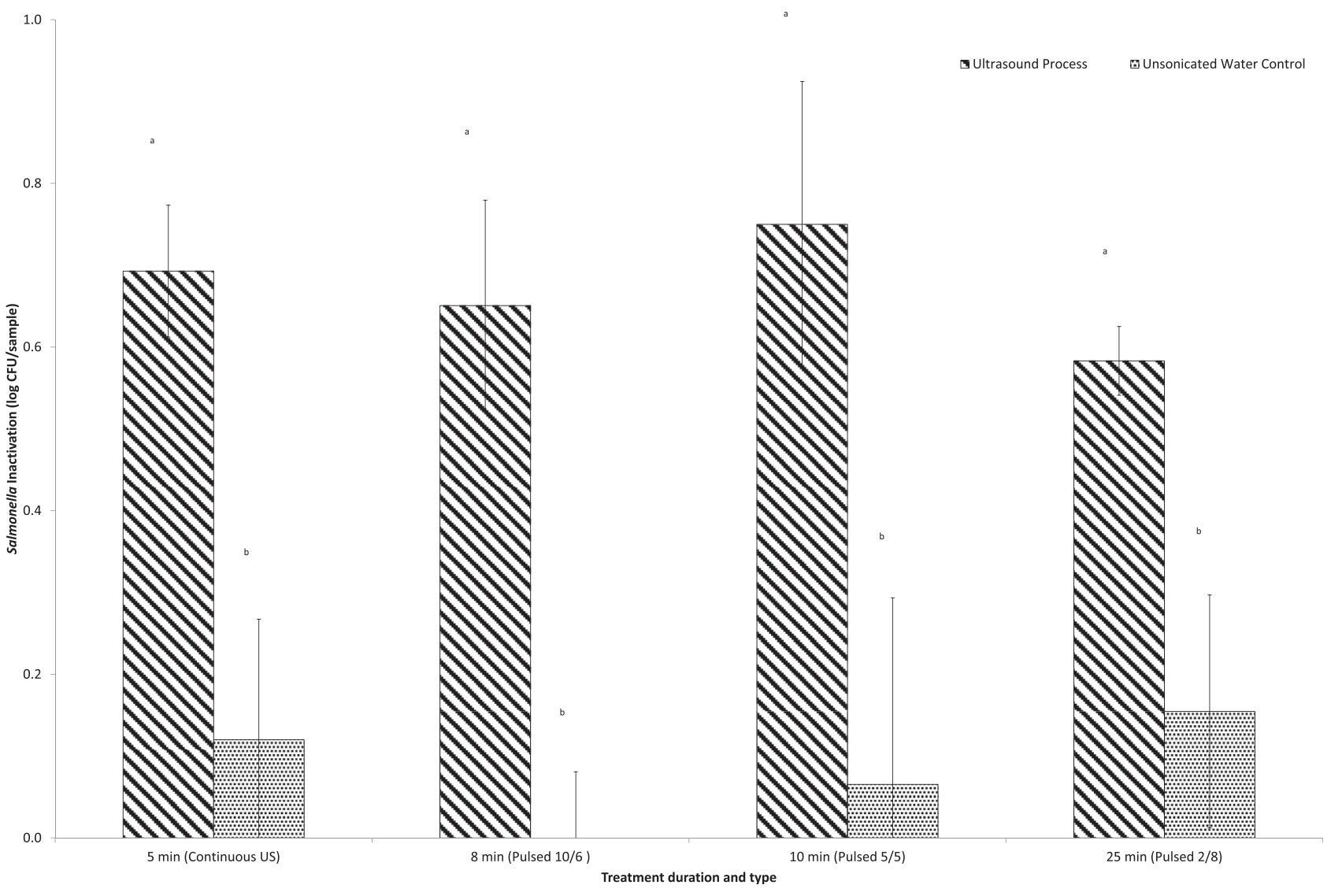

Fig. 2. Inactivation levels of Salmonella enterica after washing with water or ultrasound treatment $(p<0.01)$. 
Table 1

Levels of Salmonella reduction $\left(\log \mathrm{CFU} / \mathrm{cm}^{2}\right)$ on the surface of the lettuce and total inactivation (log CFU/sample) of the tested essential oils.

\begin{tabular}{|c|c|c|c|c|c|c|c|c|}
\hline & \multicolumn{4}{|c|}{ EOT } & \multicolumn{4}{|c|}{ EOO } \\
\hline & \multicolumn{2}{|c|}{$5 \mathrm{~min}$} & \multicolumn{2}{|c|}{$25 \mathrm{~min}$} & \multicolumn{2}{|c|}{$5 \mathrm{~min}$} & \multicolumn{2}{|c|}{$25 \mathrm{~min}$} \\
\hline & Reduction & Inactivation & Reduction & Inactivation & Reduction & Inactivation & Reduction & Inactivation \\
\hline $0.010 \%$ & $2.97 \pm 0.31$ & $0.66 \pm 0.23$ & $1.64 \pm 0.17$ & $0.53 \pm 0.46$ & $2.61 \pm 0.31$ & $0.69 \pm 0.22$ & $1.88 \pm 0.33$ & $0.48 \pm 0.42$ \\
\hline $0.014 \%$ & $3.04 \pm 0.45$ & $0.63 \pm 0.17$ & $2.48 \pm 0.16$ & $0.81 \pm 0.46$ & $2.96 \pm 0.55$ & $0.70 \pm 0.17$ & $2.63 \pm 0.68$ & $0.91 \pm 0.41$ \\
\hline $0.018 \%$ & $3.62 \pm 0.39$ & $0.87 \pm 0.17$ & $2.59 \pm 0.20$ & $0.88 \pm 0.43$ & $2.92 \pm 0.31$ & $0.75 \pm 0.19$ & $2.86 \pm 0.24$ & $0.77 \pm 0.42$ \\
\hline $0.022 \%$ & $3.73 \pm 0.61$ & $0.28 \pm 0.21$ & $3.29 \pm 0.27$ & $0.57 \pm 0.44$ & BLD & $0.88 \pm 0.47$ & $3.21 \pm 0.24$ & $0.88 \pm 0.47$ \\
\hline $0.025 \%$ & BLD & $0.87 \pm 0.22$ & $4.12 \pm 0.27$ & $0.65 \pm 0.42$ & BLD & $0.96 \pm 0.41$ & $5.38 \pm 0.23$ & $0.74 \pm 0.47$ \\
\hline
\end{tabular}

a particle size between 48.08 and $91.87 \mathrm{~nm}$ while pulsed ultrasound generated droplets between 36.61 and $132.90 \mathrm{~nm}$. No statistical differences were observed between the sizes of droplets generated by the studied ultrasound configurations. Additionally, no trends were observed when the concentration of the tested essential oil increased. The $\mathrm{z}$-potentials of the generated nanoemulsions were between 25 and $50 \mathrm{mV}$ (Table 2). Overall, z-potential values of EOT particles showed a higher charge than those of EOO. Sonicated water had $\mathrm{a} \mathrm{pH}$ of $6.16 \pm 0.20$ for continuous ultrasound and $5.78 \pm 0.0 .15$ for pulsed ultrasound (Table 2). The $\mathrm{pH}$ value decreased slightly when the concentration of EOT or EOO increased. Moreover, EOT dispersions had a lower pH than EOO nanoemulsions at all concentration tested.

\subsection{Electrolyte leakage rate}

The electrolyte leakage rate of the lettuce samples treated by the different ultrasound configurations (continuous or pulsed) showed similar values to the control samples (Table 3). When essential oils were added, the electrolyte rate increased notably (Table 4) both for the controls and treated samples, showing the presence of the essential oil on the surface of the lettuce.

\section{Discussion}

According to the obtained results, washing fresh produce with water is an inefficient method to reduce and inactivate the levels of Salmonella population on lettuce leaves. Ultrasound treatments alone or washing with essential oils can enhance the levels of bacteria reduction on the surface of the fresh produce. However, the bacteria detached from the surface of the food product may be released into the surrounding water and may have the ability to cross-contaminate the new batch of fresh produce. Therefore, studying the total inactivation of the process is important in order

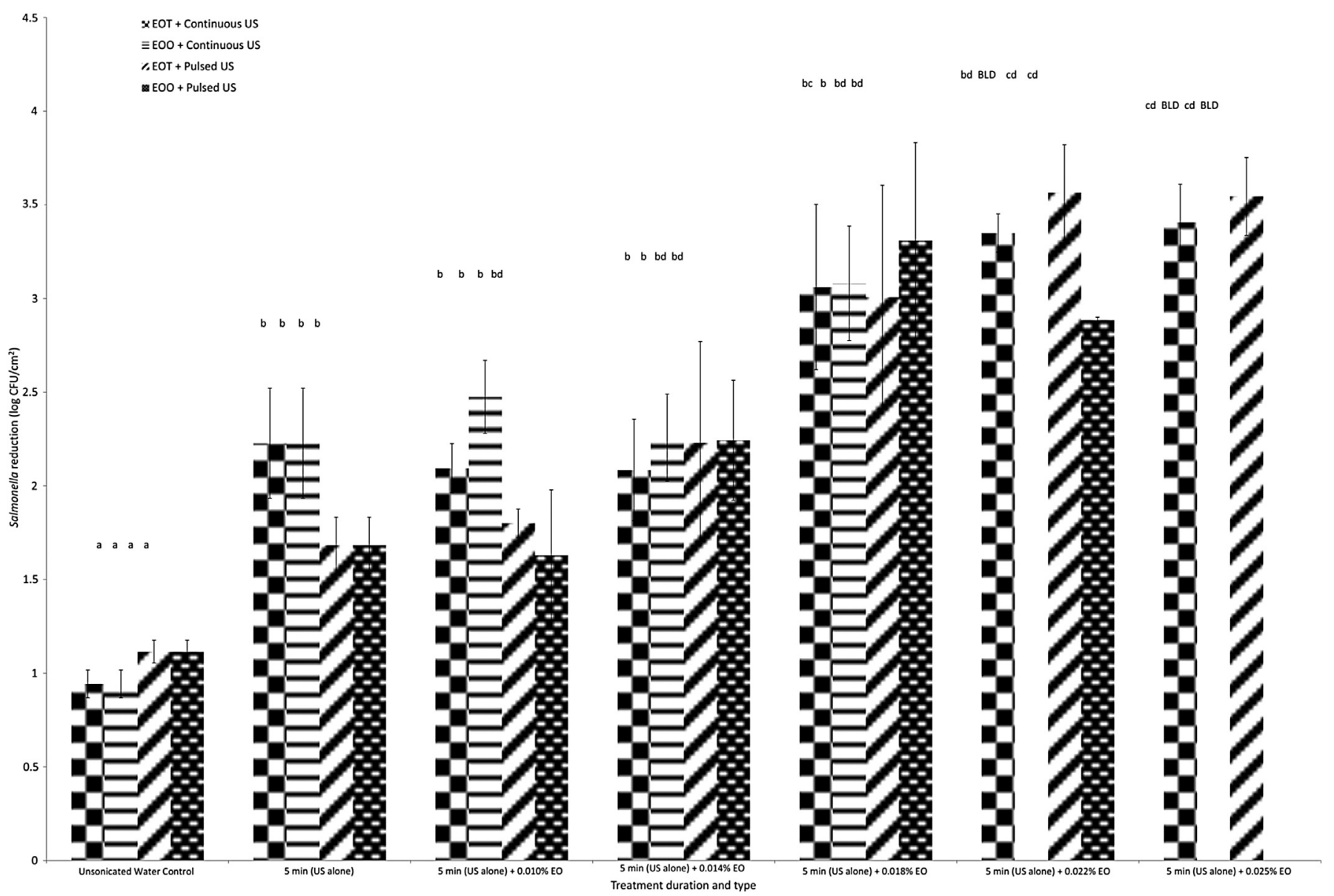

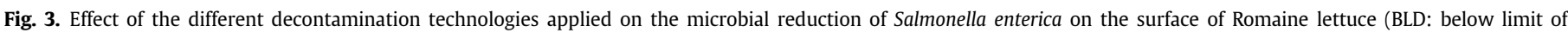
detection) (Different letters indicate significant differences $(p<0.01))$. 


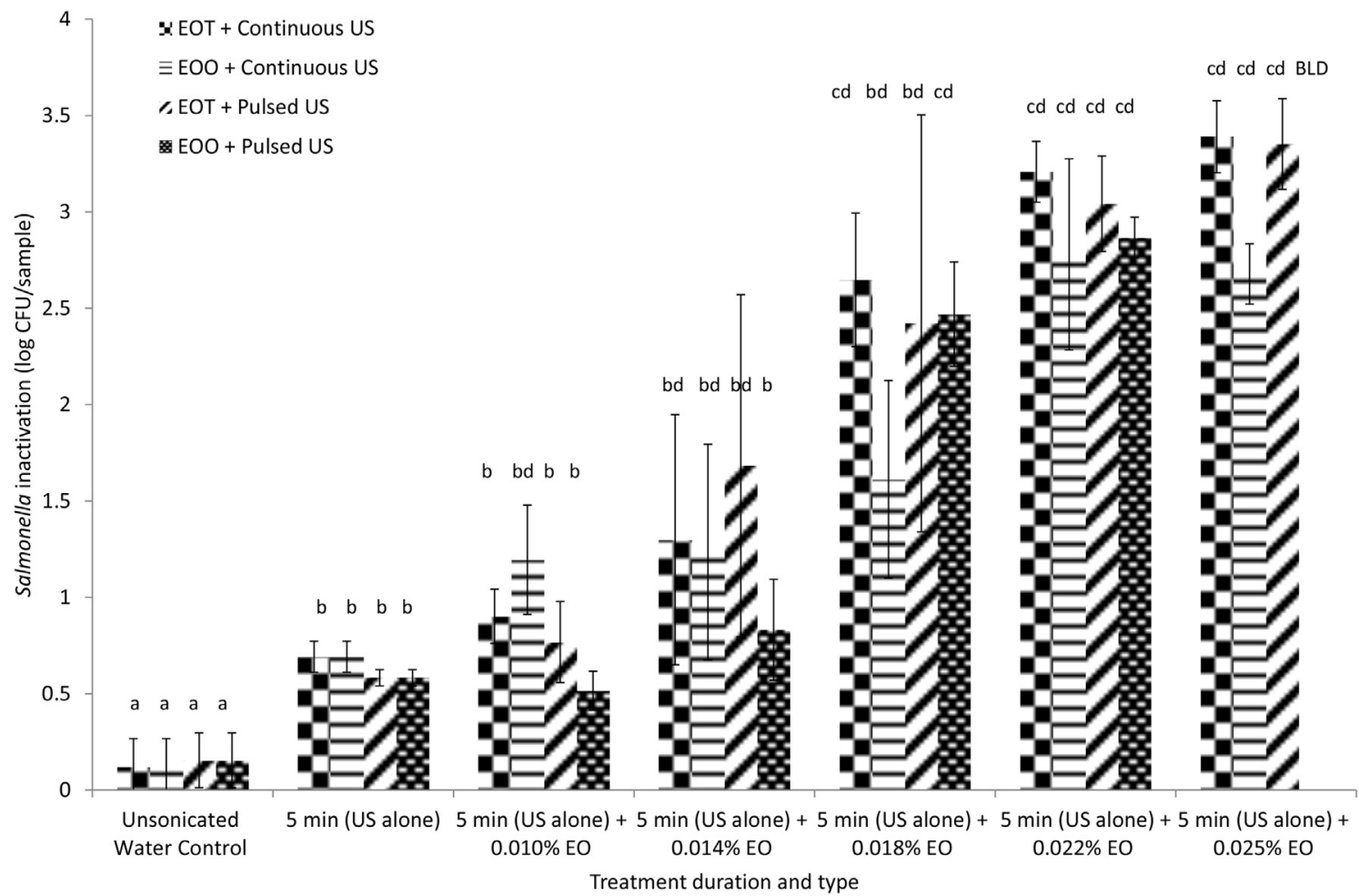

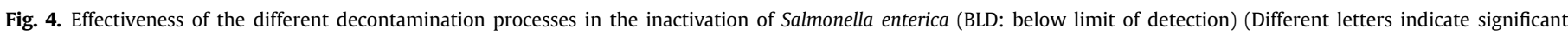
differences $(p<0.01))$.

Table 2

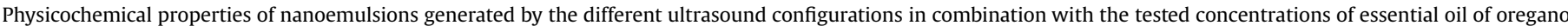
and thyme.

\begin{tabular}{|c|c|c|c|c|c|c|}
\hline \multicolumn{7}{|c|}{ Essential oil of oregano (R.I. $=1.51487$ ) } \\
\hline \multirow[t]{2}{*}{ Concentration } & \multicolumn{3}{|c|}{ Continuous ultrasound } & \multicolumn{3}{|l|}{ Pulse ultrasound } \\
\hline & Particle size (nm) & Zeta potential (mV) & $\mathrm{pH}$ & Particle size (nm) & Zeta potential (mV) & $\mathrm{pH}$ \\
\hline No E.O. & - & - & $6.16 \pm 0.20$ & - & - & $5.79 \pm 0.15$ \\
\hline $0.010 \%(v / v)$ & 68.06 & $-29.60 \pm 2.68$ & $5.67 \pm 0.05$ & 44.07 & $-29.43 \pm 1.33$ & $5.61 \pm 0.05$ \\
\hline $0.014 \%(\mathrm{v} / \mathrm{v})$ & 69.76 & $-25.93 \pm 4.88$ & $5.59 \pm 0.04$ & 53.06 & $-26.00 \pm 5.465$ & $5.55 \pm 0.05$ \\
\hline $0.018 \%(\mathrm{v} / \mathrm{v})$ & 90.17 & $-29.70 \pm 4.94$ & $5.60 \pm 0.03$ & 108.8 & $-28.17 \pm 1.69$ & $5.54 \pm 0.01$ \\
\hline $0.018 \%(\mathrm{v} / \mathrm{v})$ & 96.42 & $-35.03 \pm 4.37$ & $5.53 \pm 0.03$ & 79.86 & $-29.9 \pm 0.55$ & $5.51 \pm 0.08$ \\
\hline $0.025 \%(\mathrm{v} / \mathrm{v})$ & 105.7 & $-35.6 \pm 3.73$ & $5.50 \pm 0.02$ & 90.28 & $-30.4 \pm 1.49$ & $5.43 \pm 0.03$ \\
\hline \multicolumn{7}{|c|}{ Essential oil of thyme (R.I. $=1.50084)$} \\
\hline \multirow[t]{2}{*}{ Concentration } & \multicolumn{3}{|c|}{ Continuous ultrasound } & \multicolumn{3}{|l|}{ Pulse ultrasound } \\
\hline & Particle size (nm) & Zeta potential $(\mathrm{mV})$ & $\mathrm{pH}$ & Particle size (nm) & Zeta potential (mV) & $\mathrm{pH}$ \\
\hline No E.O. & - & - & $6.16 \pm 0.20$ & - & - & $5.79 \pm 0.15$ \\
\hline $0.010 \%(\mathrm{v} / \mathrm{v})$ & 48.08 & $-32.00 \pm 2.34$ & $5.66 \pm 0.10$ & 51.17 & $-29.33 \pm 6.86$ & $5.50 \pm 0.02$ \\
\hline $0.014 \%(\mathrm{v} / \mathrm{v})$ & 81.85 & $-39.10 \pm 2.36$ & $5.49 \pm 0.04$ & 66.18 & $-33.20 \pm 3.18$ & $5.41 \pm 0.07$ \\
\hline $0.018 \%(\mathrm{v} / \mathrm{v})$ & 70.76 & $-47.20 \pm 2.02$ & $5.51 \pm 0.05$ & 89.44 & $-29.43 \pm 4.60$ & $5.39 \pm 0.07$ \\
\hline $0.018 \%(\mathrm{v} / \mathrm{v})$ & 71.1 & $-41.53 \pm 2.39$ & $5.50 \pm 0.07$ & 35.61 & $-27.77 \pm 3.62$ & $5.40 \pm 0.01$ \\
\hline $0.025 \%(\mathrm{v} / \mathrm{v})$ & 91.87 & $-33.97 \pm 3.62$ & $5.38 \pm 0.05$ & 132.9 & $-33.13 \pm 1.64$ & $5.41 \pm 0.09$ \\
\hline
\end{tabular}

to develop a sound and safe decontamination process. The experimental findings of this research have shown that the application of both treatments separately is not effective in killing bacteria (less than $1 \log$ CFU/sample).
In order to increase the efficacy of the process, both treatments were simultaneously combined. A synergistic effect of bacterial inactivation were observed when the concentration of essential oils tested was $0.018 \%$ or higher compared with samples without

Table 3

Electrolyte leakage rate of lettuce control samples and ultrasound treated samples (Different letters indicate significant differences $(p<0.01)$ ).

\begin{tabular}{|c|c|c|c|}
\hline Control & $2.37 \pm 0.36^{\mathrm{a}}$ & Control & $3.14 \pm 0.71^{\mathrm{a}}$ \\
\hline Continuous Ultrasound & $1.69 \pm 0.37^{\mathrm{a}}$ & Pulsed $5 \mathrm{~s}$ on $/ 5 \mathrm{~s}$ off Ultrasound & $2.67 \pm 0.63^{\mathrm{a}}$ \\
\hline Control & $1.74 \pm 0.49^{\mathrm{a}}$ & Control & $2.16 \pm 0.17^{\mathrm{a}}$ \\
\hline Pulsed $10 \mathrm{~s}$ on $/ 6 \mathrm{~s}$ off Ultrasound & $2.55 \pm 0.50^{\mathrm{a}}$ & Pulsed $2 \mathrm{~s}$ on $/ 8 \mathrm{~s}$ off Ultrasound & $1.66 \pm 0.68^{a}$ \\
\hline
\end{tabular}


Table 4

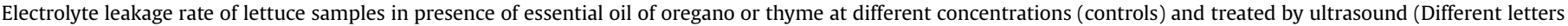
indicate significant differences $(p<0.01)$ ).

\begin{tabular}{|c|c|c|c|c|}
\hline & \multicolumn{2}{|c|}{ Continuous ultrasound } & \multicolumn{2}{|c|}{ Pulsed ultrasound } \\
\hline & Essential oil of Oregano & Essential oil of thyme & Essential oil of Oregano & Essential oil of thyme \\
\hline Control & $15.15 \pm 4.48^{\mathrm{a}}$ & $9.85 \pm 0.17^{\mathrm{a}}$ & $11.32 \pm 3.02^{\mathrm{a}}$ & $15.35 \pm 0.14^{\mathrm{a}}$ \\
\hline $0.010 \%(\mathrm{v} / \mathrm{v})$ & $15.51 \pm 2.22^{\mathrm{a}}$ & $21.82 \pm 2.63^{\mathrm{a}}$ & $11.45 \pm 0.61^{\mathrm{a}}$ & $15.95 \pm 0.49^{\mathrm{a}}$ \\
\hline Control & $9.16 \pm 1.13^{\mathrm{a}}$ & $10.45 \pm 2.51^{\mathrm{a}}$ & $11.45 \pm 0.61^{\mathrm{a}}$ & $15.52 \pm 1.39^{\mathrm{a}}$ \\
\hline $0.014 \%(\mathrm{v} / \mathrm{v})$ & $13.35 \pm 2.43^{\mathrm{a}}$ & $24.01 \pm 1.15^{\mathrm{a}}$ & $14.90 \pm 0.87^{\mathrm{a}}$ & $18.66 \pm 1.40^{\mathrm{a}}$ \\
\hline Control & $12.86 \pm 1.38^{\mathrm{a}}$ & $12.33 \pm 1.41^{\mathrm{a}}$ & $12.98 \pm 0.91^{\mathrm{a}}$ & $12.23 \pm 1.13^{\mathrm{a}}$ \\
\hline $0.018 \%(\mathrm{v} / \mathrm{v})$ & $20.91 \pm 3.43^{\mathrm{a}}$ & $23.71 \pm 5.85^{\mathrm{a}}$ & $15.88 \pm 0.59^{\mathrm{a}}$ & $16.03 \pm 0.88^{a}$ \\
\hline Control & $19.73 \pm 7.49^{\mathrm{a}}$ & $20.81 \pm 8.97^{\mathrm{a}}$ & $23.56 \pm 6.25^{a}$ & $13.59 \pm 0.67^{\mathrm{a}}$ \\
\hline $0.022 \%(\mathrm{v} / \mathrm{v})$ & $21.88 \pm 6.27^{\mathrm{a}}$ & $30.74 \pm 2.15^{\mathrm{a}}$ & $22.42 \pm 2.61^{\mathrm{a}}$ & $31.36 \pm 2.29^{\mathrm{a}}$ \\
\hline Control & $16.70 \pm 5.56^{\mathrm{a}}$ & $24.88 \pm 7.05^{a}$ & $13.01 \pm 3.51^{\mathrm{a}}$ & $11.50 \pm 2.29^{\mathrm{a}}$ \\
\hline $0.025 \%(\mathrm{v} / \mathrm{v})$ & $21.35 \pm 5.97^{\mathrm{a}}$ & $37.60 \pm 4.30^{\mathrm{a}}$ & $14.70 \pm 4.53^{\mathrm{a}}$ & $30.60 \pm 8.12^{\mathrm{a}}$ \\
\hline
\end{tabular}

essential oil. Juven, Kanner, Schved, and Weisslowicz (1994) stated that significant inactivation of Salmonella Typhimurium was observed when a critical concentration of carvacrol or thymol was achieved. At this critical concentration, carvacrol or thymol sensitize the bacteria membrane producing a saturation of the site of action, generating a gross damage and a sudden collapse of the integrity of the bacterial cytoplasmic membrane and therefore the leakage of vital intracellular constituents (Juven et al. 1994). Furthermore, the low $\mathrm{pH}$ of these concentrations can play an important role regarding the efficacy of the phenolic components. Juven et al. (1994) stated that the inhibitory effect of thymol was higher at a more acidic $\mathrm{pH}$ since when the antimicrobial agent of the essential oil is undissociated, it binds better to the hydrophobic parts of the proteins of the cell membrane and the dissolution of the lipid membrane can take place more easily. Hence, this $\mathrm{pH}$ acidification entails better action of the antimicrobial substances of the essential oil, especially when the critical concentration of the essential oils is achieved at high levels of Salmonella inactivation.

The size of the droplets of essential oil generated during the sonication process depends on the ultrasound parameters (amplitude, frequency and processing time) (Salvia-Trujillo, Rojas-Graü, Soliva-Fortuny, \& Martín-Belloso, 2015) and may have an effect on the antimicrobial properties of the oil. Some authors have reported that a smaller particle size has a positive influence on the oil's biological properties (Speranza, Badan Ribeiro, Lopes Cunha, Alves Macedo, \& Alves Macedo, 2015, McClements \& Xiao, 2012, Teixeira et al., 2007). However, other authors have reported no influence of the droplet size on the activity of the nanoemulsion generated (Salvia-Trujillo, Rojas-Graü, Soliva-Fortuny, \& MartínBelloso, 2014, Buranasuksombat, Kwon, Turner, \& Bhandari, 2011). This study is in accordance with the latter publications as statistical analysis has shown that the antimicrobial efficacy of the essential oils studied depends on the applied concentration rather the particle sizes generated in the oil-water nanoemulsion during the sonication process. Additionally, a negative Z-potential of all nanoemulsions generated which is related to the differences in the number of ionizable components and the degree of dissociation of the studied essential oils (Bonilla, Atarés, Vargas, \& Chiralt, 2012) was observed.

Electrolyte leakage rate measures the cell membrane integrity (Duan, Jiang, Su, Zhang, \& Shi, 2007). Ultrasound alone treatment had no impact on the lettuce according to the results obtained from the electrolyte leakage rate. In the same way, cross sections and SEM images obtained by Millan-Sango, McElhatton, and Valdramidis (2015) have shown no damage to the lettuce leaves by ultrasound treatment. However, when essential oils were applied both controls and treated samples electrolyte leakage values of the samples increased notably. Millan-Sango et al. (2015) reported the presence of droplets of essential oil based on SEM analysis after the ultrasound treatment combined with EOO. Hence, this increment may be related to the presence of essential oils on the surface of the lettuce after the process rather than to a damage of the biological structure of the lettuce's cells. Moreover, the presence of essential oil globules after the sonication process could result in additional bacterial inactivation during storage. A study carried out by Moore-Neibel et al. (2013) reported further Salmonella enterica reduction on inoculated Romain lettuce during storage time after washing with oregano essential oil. However, further research has to be carried out to evaluate how those decontamination technologies affect both the organoleptic and quality parameters of the lettuce.

\section{Conclusion}

According to the current results, ultrasound seems to be a potential decontamination technology for fresh produce. Moreover, ultrasound combined with essential oil enhanced both the reduction and inactivation, especially when a critical concentration was achieved. A synergetic effect on the total bacteria inactivation was observed when a critical concentration was reached. Particle sizes of the essential oil nanoemulsions generated had no influence on the decontamination process. In addition, no cell damage on the vegetable tissue was evident after the ultrasound process. Further research regarding the organoleptic and quality parameters during storage will need to be carried out. Discriminating the exact impact of cavitation and sonolysis could be further addressed by measuring for example the chemical compounds produced by the effect of sonolysis.

\section{Acknowledgment}

This research was supported by a Marie Curie FP7Reintegration-Grant within the 7th European Community Framework Programme under the project Development of novel Disinfection Technologies for Fresh Produce (DiTec) (303939), while it is partly funded by the COST ACTION FA1202 BacFoodNet (1202).

\section{References}

Allende, A., Tomás-Barberán, F. A., \& Gil, M. I. (2006). Minimal processing for healthy traditional foods. Trends in Food Science \& Technology, 17, 513-519.

Awad, T., Moharram, H., Shaltout, O., Asker, D., \& Youssef, M. (2012). Applications of ultrasound in analysis, processing and quality control of food: a review. Food Research International, 48, 410-427.

Bonilla, J., Atarés, L., Vargas, M., \& Chiralt, A. (2012). Effect of essential oils and homogenization conditions on properties of chitosan-based films. Food $\mathrm{Hy}$ drocolloids, 26, 9-16.

Buranasuksombat, U., Kwon, Y. J., Turner, M., \& Bhandari, B. (2011). Influence of emulsion droplet size on antimicrobial properties. Food Science and Biotechnology, 20, 793-800. 
Callejón, R. M., Rodríguez-Naranjo, M. I., Ubeda, C., Hornedo-Ortega, R., GarciaParrilla, M. C., \& Troncoso, A. M. (2015). Reported foodborne outbreaks due to fresh produce in the United States and European Union: trends and causes. Foodborne Pathogens and Disease, 12, 32-38.

Chemat, F., \& Khan, M. K. (2011). Applications of ultrasound in food technology: processing, preservation and extraction. Ultrasonics Sonochemistry, 18, 813-835.

Cosentino, S., Tuberoso, C., Pisano, B., Satta, M., Mascia, V., Arzedi, E., et al. (1999). In-vitro antimicrobial activity and chemical composition of Sardinian thymus essential oils. Letters in Applied Microbiology, 29, 130-135.

Duan, X., Jiang, Y., Su, X., Zhang, Z., \& Shi, J. (2007). Antioxidant properties of anthocyanins extracted from litchi (Litchi chinenesis Sonn.) fruit pericarp tissues in relation to their role in the pericarp browning. Food Chemistry, 101, 1365-1371.

Dunnick, J. K., \& Melnick, R. L. (1993). Assessment of the carcinogenic potential of chlorinated water: experimental studies of chlorine, chloramine, and trihalomethanes. Journal of the National Cancer Institute, 85, 817-822.

Fan, X., \& Sokorai, K. J. (2005). Assessment of radiation sensitivity of fresh-cut vegetables using electrolyte leakage measurement. Postharvest Biology and Technology, 36, 191-197.

Fernandez, A., Noriega, E., \& Thompson, A. (2013). Inactivation of Salmonella enterica serovar Typhimurium on fresh produce by cold atmospheric gas plasma technology. Food Microbiology, 33, 24-29.

Gil, M. I., Selma, M. V., López-Gálvez, F., \& Allende, A. (2009). Fresh-cut product sanitation and wash water disinfection: problems and solutions. International Journal of Food Microbiology, 134, 37-45.

Gómez-López, V. M., Rajkovic, A., Ragaert, P., Smigic, N., \& Devlieghere, F. (2009) Chlorine dioxide for minimally processed produce preservation: a review. Trends in Food Science \& Technology, 20, 17-26.

Gustafson, J. E., Liew, Y. C., Chew, S., Markham, J., Bell, H. C., Wyllie, S. G., et al. (1998). Effects of tea tree oil on Escherichia coli. Letters in Applied Microbiology, 26, 194-198.

Helander, I. M., Alakomi, H., Latva-Kala, K., Mattila-Sandholm, T., Pol, I., Smid, E. J., et al. (1998). Characterization of the action of selected essential oil components on Gram-negative bacteria. Journal of Agricultural and Food Chemistry, 46, 3590-3595.

Jackson, B. R., Griffin, P. M., Cole, D., Walsh, K. A., \& Chai, S. J. (2013). Outbreakassociated Salmonella enterica serotypes and food Commodities, United States, 1998-2008. Emerging Infectious Diseases, 19, 1239-1244.

Juven, B., Kanner, J., Schved, F., \& Weisslowicz, H. (1994). Factors that interact with the antibacterial action of thyme essential oil and its active constituents. Journal of Applied Bacteriology, 76, 626-631.

Lambert, R., Skandamis, P. N., Coote, P. J., \& Nychas, G. (2001). A study of the minimum inhibitory concentration and mode of action of oregano essential oil, thymol and carvacrol. Journal of Applied Microbiology, 91, 453-462.

McClements, D. J., \& Xiao, H. (2012). Potential biological fate of ingested nanoemulsions: influence of particle characteristics. Food \& Function, 3, 202-220.

Millan-Sango, D., McElhatton, A., \& Valdramidis, V. P. (2015). Determination of the efficacy of ultrasound in combination with essential oil of oregano for the decontamination of Escherichia coli on inoculated lettuce leaves. Food Research
International, 67, 145-154.

Moore-Neibel, K., Gerber, C., Patel, J., Friedman, M., Jaroni, D., \& Ravishankar, S, (2013). Antimicrobial activity of oregano oil against antibiotic-resistant Salmonella enterica on organic leafy greens at varying exposure times and storage temperatures. Food Microbiology, 34, 123-129.

Mukhopadhyay, S., \& Ramaswamy, R. (2012). Application of emerging technologies to control Salmonella in foods: a review. Food Research International, 45, 666-677.

Ölmez, H., \& Kretzschmar, U. (2009). Potential alternative disinfection methods for organic fresh-cut industry for minimizing water consumption and environmental impact. LWT-Food Science and Technology, 42, 686-693.

Piyasena, P., Mohareb, E., \& McKellar, R. (2003). Inactivation of microbes using ultrasound: a review. International Journal of Food Microbiology 87(3), 207-216.

Rico, D., Martin-Diana, A. B., Barat, J., \& Barry-Ryan, C. (2007). Extending and measuring the quality of fresh-cut fruit and vegetables: a review. Trends in Food Science \& Technology, 18, 373-386.

Riesz, P., Berdahl, D., \& Christman, C. L. (1985). Free radical generation by ultrasound in aqueous and nonaqueous solutions. Environmental Health Perspectives, 64, $233-252$.

Salvia-Trujillo, L., Rojas-Graü, M. A., Soliva-Fortuny, R., \& Martín-Belloso, O. (2014). Impact of microfluidization or ultrasound processing on the antimicrobial activity against Escherichia coli of lemongrass oil-loaded nanoemulsions. Food Control, 37, 292-297.

Salvia-Trujillo, L., Rojas-Graü, A., Soliva-Fortuny, R., \& Martín-Belloso, O. (2015). Physicochemical characterization and antimicrobial activity of food-grade emulsions and nanoemulsions incorporating essential oils. Food Hydrocolloids, 43, 547-556.

Sango, D., Abela, D., McElhatton, A., \& Valdramidis, V. (2014). Assisted ultrasound applications for the production of safe foods. Journal of Applied Microbiology, $116,1067-1083$

Seymour, I., Burfoot, D., Smith, R., Cox, L., \& Lockwood, A. (2002). Ultrasound decontamination of minimally processed fruits and vegetables. International Journal of Food Science \& Technology, 37, 547-557.

Solans, C., Izquierdo, P., Nolla, J., Azemar, N., \& Garcia-Celma, M. (2005). Nanoemulsions. Current Opinion in Colloid \& Interface Science, 10, 102-110.

Speranza, P., Ribeiro, A. P. B., Cunha, R. L., Macedo, J. A., \& Macedo, G. A. (2015). Influence of emulsion droplet size on antimicrobial activity of interesterified Amazonian oils. LWT-Food Science and Technology, 60, 207-212.

Teixeira, P. C., Leite, G. M., Domingues, R. J., Silva, J., Gibbs, P. A., \& Ferreira, J. P. (2007). Antimicrobial effects of a microemulsion and a nanoemulsion on enteric and other pathogens and biofilms. International Journal of Food Microbiology, 118, 15-19.

Ultee, A., Kets, E. P., \& Smid, E. J. (1999). Mechanisms of action of carvacrol on the food-borne pathogen Bacillus cereus. Applied and Environmental Microbiology, $65,4606-4610$

Ultee, A., \& Smid, E. (2001). Influence of carvacrol on growth and toxin production by Bacillus cereus. International Journal of Food Microbiology, 64, 373-378. 